\title{
PREPARATION AND CHARACTERIZATION OF CHITOSAN/AGAR BLENDS: RHEOLOGICAL AND THERMAL STUDIES
}

\author{
ESAM. A. EL-HEFIAN ${ }^{* 1}$, MOHAMED MAHMOUD NASEF ${ }^{2}$, ABDUL HAMID YAHAYA ${ }^{1}$ AND \\ RASHID ATTA KHAN
}

\author{
${ }^{1}$ Department of Chemistry, Faculty of Science, University of Malaya, 50603 Kuala Lumpur, Malaysia \\ ${ }^{2}$ Chemical Engineering Department, Faculty of Chemical and Natural Resources Engineering, Universiti Teknologi Malaysia, \\ 81310 UTM Skudai, Johor, Malaysia \\ (Received: July 21, 2009 - Accepted: January 6, 2010)
}

\begin{abstract}
In this work, a number of mixture aqueous solutions of chitosan/agar (CS/AG) at different ratios (considering chitosan as the main component) were prepared. The rheological properties i.e. shearing viscosity and shear stress of the blend solutions as a function of shear rate as well as the thermal properties of the blend films were investigated. Among the parameters studied were temperature, shearing time and storage time. Results showed that almost Newtonian behavior was observed at temperatures from $40^{\circ} \mathrm{C}$ to $55^{\circ} \mathrm{C}$ for the ratios $100 / 0,90 / 10,80 / 20$ and $70 / 30$. However, the proportions $60 / 40$ and $50 / 50$ showed a clear shear thinning behavior (pseudoplastic non-Newtonian behavior). It was also found that all the blend solutions obeyed the Arrhenius equation. In addition, the effect of shearing time on the shearing viscosity of all blends did not show any significant differences at all shearing times applied in this study except the proportion 50/50 wherein decreasing in shearing viscosity and shear stress was observed as the shearing time increased. Furthermore, different behaviors were observed for the blend solutions when the period of storage was extended to three weeks. The FTIR results and the differential scanning calorimetery (DSC) curves showed that the interaction between chitosan and agar can occur.
\end{abstract}

\section{INTRODUCTION}

Polymeric material has been extensively used in our daily life. Recently, polymer blends have received much attention. This is mainly due to the fact that new materials with better physicochemical properties can be observed when the individual components used to blend are compatible [1,2]. Modification of chitosan by blending with other polymeric materials might be of interest for some applications. Lots of chitosan blends and composites with other polymers have been proposed in the literature, for example, chitosan/cellulose membrane [3,4], chitosan/starch [5], chitosan/gelatin [6] and chitosan/collagen [7]. The compatibility of chitosan with these polymers may be obtained since chitosan is considered as a strongly interacting polymer [8].

Chitosan, $1 \rightarrow 4$ linked 2 - amino, 2 - deoxy, $\beta$ - D - glucan, is a polycationic derived from chitin by alkaline deacetylation [9]. Due to the amino groups that chitosan possesses in its chain, it can be dissolved in dilute aqueous acid solutions, such as acetic acid and propionic acid. Since it is inexpensive, non-toxic and possesses potentially reactive amino functional groups, chitosan has been evaluated for numerous applications, including medicine, food, cosmetics and wastewater treatment [10-14].

Agar is a mixture of polysaccharides which is extracted from the family of seaweeds (Rhodophycae). It mainly consists of agarose and agaropectin [15]. The former governs the gelling ability of agar. The latter includes ionic groups such as sulfate and methoxy groups. The most important property of agar is its ability to form reversible gels simply by cooling hot aqueous solutions due to the formation of hydrogen bonds [16-18]. Some of its hydrogel blends, such as PVP-agar hydrogel, have already been prepared [19]. Agar has a wide variety of uses in industry. For example, it has been used in the food area (processed cheese, ice cream, bread and soft candy) due to its ability to form hard gels at very low concentration $[20,21]$.

The rheological behavior of chitosan solutions [22-25] as well its thermal decomposition and stability [26-29] have been already reported in the literature. However, to our knowledge, no much work has been done on chitosan/agar blends. Therefore, the present work is aimed at studying the rheological properties, i.e, the effects of shear rate, temperature, shearing time and storage time on the shearing viscosities and shear stresses of aqueous solutions of chitosan/agar blends at different proportions. This work is also aimed at studying the thermal properties of chitosan/agar films with the view to further explore the thin film properties and its applications.

\section{EXPERIMENTAL}

\section{Materials}

Shrimp source chitosan was purchased from a local company with a deacetylation percentage (DD) of $88.1 \%$ defined by UV method [30]. This chitosan was acid soluble, white-colored and flaky. Agar was purchased from Sigma. Acetic acid (glacial 100\%, pro analysi) was purchased from Merck (Darmstadt, Germany). Ultra pure water (Maxima Ultra Pure Water, ElgaPrima Corp, UK) with a resistivity greater than $18 \mathrm{M} \Omega / \mathrm{cm}$ was used to prepare all solutions. All chemicals were used without further purification and freshly prepared solutions were used in all experiments.

\section{Preparation of the solutions}

Chitosan was dried in the oven until a constant weight was observed. Then, $5 \mathrm{~g}$ of chitosan was dissolved in $500 \mathrm{~mL}$ acetic acid $(0.1 \mathrm{M})$ followed by mild stirring and heating at about $60^{\circ} \mathrm{C}$ overnight to form $10 \mathrm{~g} \mathrm{~L}^{-1}$ chitosan solution. The solution was then filtered to remove dust and other traces of impurities. Air bubbles were eliminated by keeping the solutions at room temperature for 2 hours.

For preparing agar solution, the same amount and procedure as for chitosan were applied with exception of using acetic acid, wherein preheated Ultra pure water was used. The solutions were then stirred and heated at about $80^{\circ} \mathrm{C}$ for 2 hours.

\section{Preparation of the blend solutions}

Blend solutions were prepared by adding the aqueous agar solution drop by drop to a chitosan solution, which was kept on a magnetic stiaring, at about $94^{\circ} \mathrm{C}$, and the mixture was stirred at a moderate speed for $30 \mathrm{~min}$. The final composition of chitosan, agar (CS/AG) varied from $90 / 10$ to $50 / 50$ by volume. Table 1 shows the designation and compositions for all the solutions prepared in this study.

Table 1: Composition of the chitosan, agar and PVA mixtures.

\begin{tabular}{|c|c|c|}
\hline Solution designation & $\mathrm{V}_{\mathrm{CS}}(\mathrm{vol} \%)$ & $\mathrm{V}_{\mathrm{AG}}(\mathrm{vol} \%)$ \\
\hline $\mathrm{CS} / \mathrm{AG}$ 90/10 & 90 & 10 \\
\hline $\mathrm{CS} / \mathrm{AG} 80 / 20$ & 80 & 20 \\
\hline $\mathrm{CS} / \mathrm{AG} \mathrm{70/30}$ & 70 & 30 \\
\hline $\mathrm{CS} / \mathrm{AG} \mathrm{60/40}$ & 60 & 40 \\
\hline CS/AG 50/50 & 50 & 50 \\
\hline
\end{tabular}




\section{Preparation of blend films}

The preparation of blend films of chitosan and agar was carried out at various proportions. The aqueous agar solution was added drop by drop to the chitosan solution, under continuous stirring at $90^{\circ} \mathrm{C}$ in various proportions by volume. The range of the added agar to chitosan solution was from $0-50 \mathrm{vol} \%$. Stirring was allowed to continue for 30 minutes after mixing. Films of the resulting homogeneous solutions were obtained by casting prescribed amounts of the solution onto polystyrene Petri dishes followed by drying at $60^{\circ} \mathrm{C}$ for 48 h. The films were peeled off and kept under evacuated desiccator over fresh silica gel until use. All films obtained were transparent and free of air bubbles.

Similar films from pure chitosan and pure agar were prepared using the same casting procedure and used as references.

\section{Film thickness}

The film thickness was measured with a digital micrometer (Mitutoyo, Japan) with $0.001 \mathrm{~mm}$ resolution. Several thickness measurements were taken at various positions on each specimen and the average value was taken.

\section{Methods}

\section{Molecular weight measurements}

The molecular weight of chitosan was about $5.5 \times 10^{5} \mathrm{~g} \mathrm{~mol}^{-1}$ determined at $30^{\circ} \mathrm{C}$ by gel permeation chromatography (GPC) equipped with a Waters 1515 HPLC Pump and a Waters 2414 Refractive Index Detector. The column used was PL aquagel-OH $30(8 \mu \mathrm{m}, 300 \times 7.5 \mathrm{~mm})$ and the solvent used was $1 \%$ acetic acid. The molecular weight of agar was about $1.3 \times 10^{4} \mathrm{~g} \mathrm{~mol}^{-1}$ determined at $70^{\circ} \mathrm{C}$ using the same method. The GPC was calibrated using pullulans as standard.

\section{Viscosity measurements}

Rheological measurements were performed on a Brookfield digital viscometer, model DV-II + Pro, with an attached UL adapter. Each of pure chitosan and pure agar solutions had a concentration of $10 \mathrm{~g} \mathrm{~L}^{-1}$ while their composition (CS/AG) ranged from $90 / 10$ to $50 / 50$ by volume. The viscosity was determined in $20 \mathrm{~mL}$ of the sample and the shearing time was 15 seconds. For the storage time measurements, solutions were kept at room temperature in glass bottles in a dark place until analysis. Each measurement was recorded as an average value of five readings when a constant shear rate was applied.

\section{FTIR measurements}

FTIR measurements of blend films $(10 \mu \mathrm{m}$ thick) were performed on a Perkin Elmer (model-2000) spectrometer. The spectra were obtained at a frequency range of 4000-400 $\mathrm{cm}^{-1}$ with a resolution of $4 \mathrm{~cm}^{-1}$ and 8 -times scanning rate.

\section{DSC measurements}

DSC studies were performed using a DSC Mettler Toledo (model DSC822e). The samples were scanned under a nitrogen atmosphere at a constant rate of $10^{\circ} \mathrm{C} / \mathrm{min}$.

\section{RESULTS AND DISCUSSION}

The effects of temperature on the shear viscosity of chitosan/agar blend solutions.

In this study, the searing rate-dependent viscosity of $\mathrm{CS} / \mathrm{AG}$ mixture solutions as a function of shear rate at a temperature range of $40^{\circ} \mathrm{C}$ to $55^{\circ} \mathrm{C}$ is presented in figures $1(\mathrm{a}-\mathrm{g})$. Higher temperatures were not applied in order to avoid thermal degradation of the polymers and solvent evaporation while lower temperatures could not be applied due to the gel formation for some mixtures. Similar to that of many polymer solutions, the behavior of the viscosity-temperature interrelationship for these mixtures show a decrease of viscosity with an increase of temperature. On the other hand, the Newtonian behavior is observed at all temperatures for the ratios 100/0, 90/10, 80/20 and $70 / 30$. However, the increase in shearing viscosity and the appearance of shear thinning behavior are clearly noticed for the ratios $60 / 40$ and 50/50. It is expected that the increase in viscosity for $\mathrm{CS} / \mathrm{AG}$ blends is attributed to the formation of hydrogen bonding due to the interaction among the functional groups of chitosan and agar $\left(-\mathrm{OH}\right.$ and $-\mathrm{NH}_{2}$ groups in chitosan and $-\mathrm{OH}$ groups in agar).

Figures 1-7 also show the effect of temperature on the shear stress of chitosan/agar mixtures as a function of shear rate. Shear stress increased with increasing shear rate for all ratios. At the same shear rate, shear stresses were higher at lower temperatures. In addition, increases in shear stress with increasing shear rate were more remarkable at lower temperatures. From the graph it is clear that only the proportions $60 / 40$ and 50/50 exhibit pseudoplastic non-Newtonian behavior. The results of pure chitosan solution obtained show some good agreement with previous studies [31]. In addition, these figures indicate that the temperature has more effect on the solutions at lower shear rate values, i.e., the viscosity increase associated with temperature is less important at high shear rates. This behavior was also reported in the literature for chitosan solutions [32].

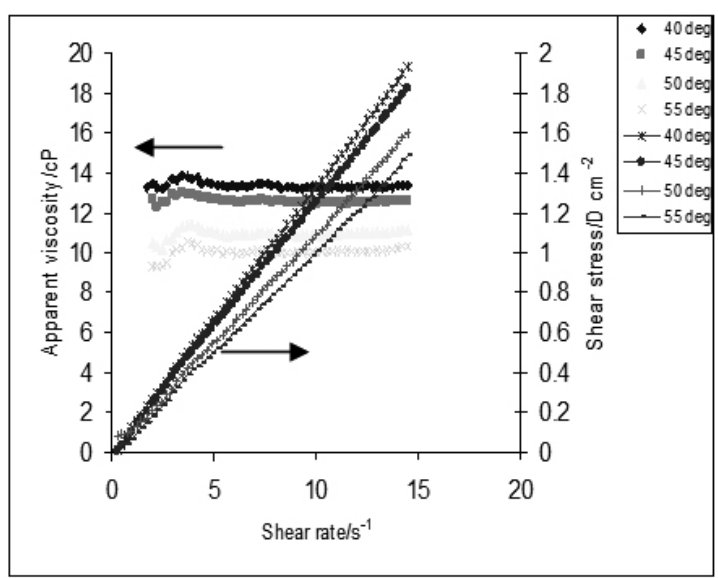

(a)

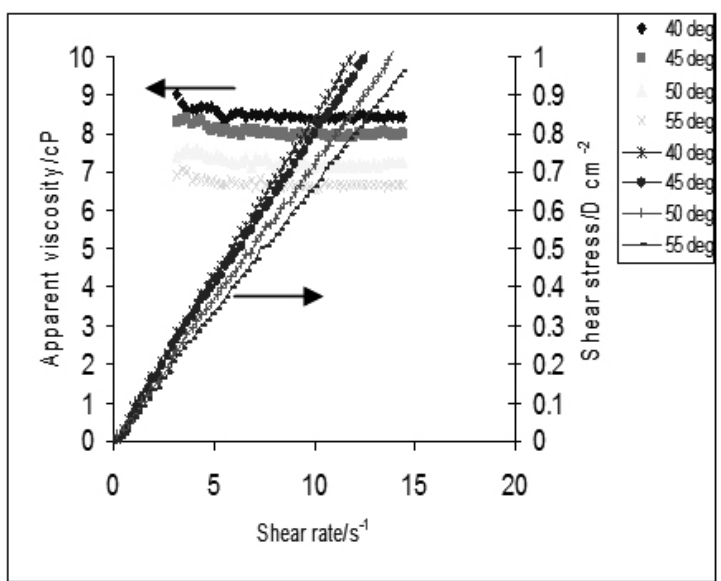

(b)

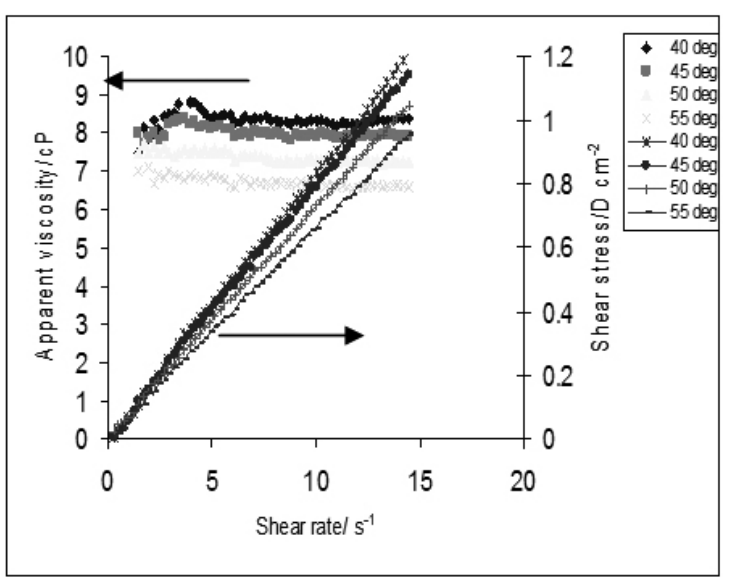

(c) 


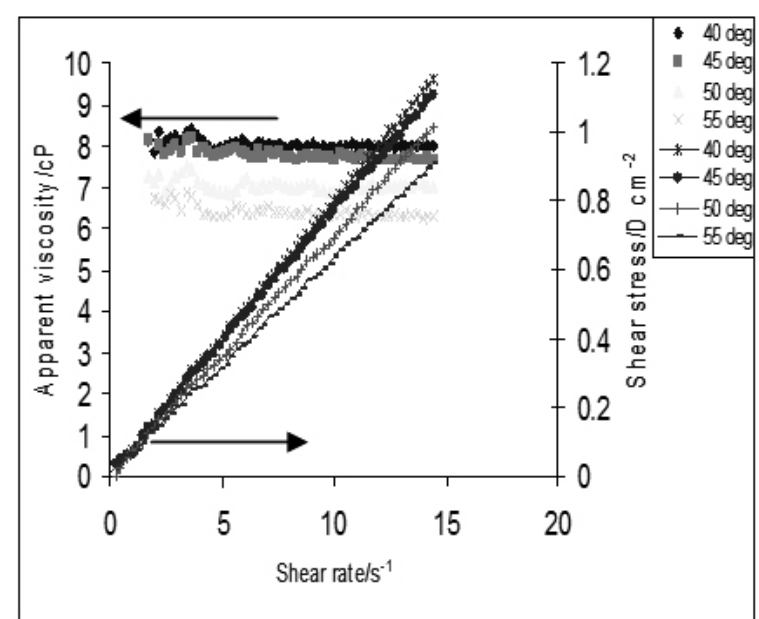

(d)

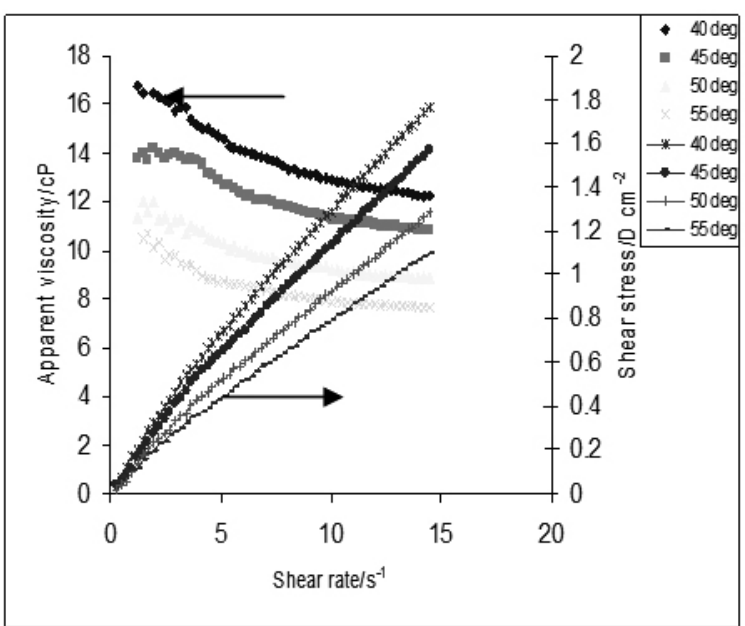

(e)

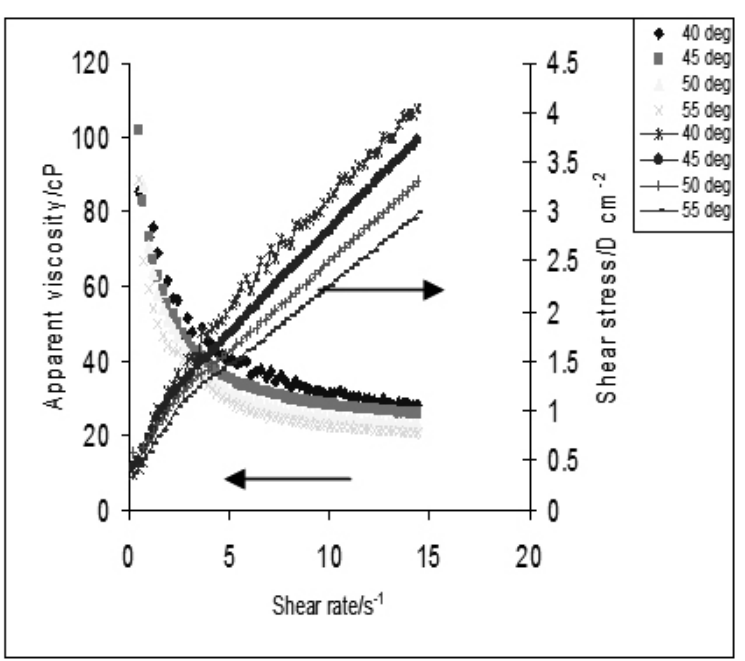

(f)

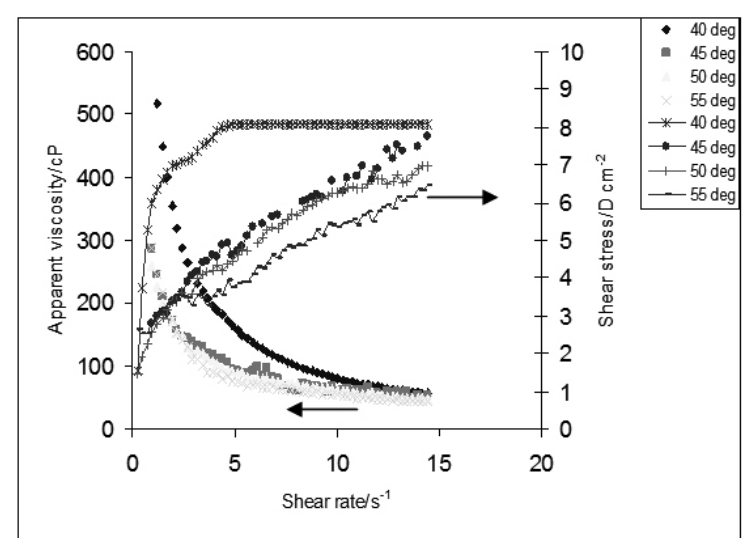

(g)

Figure 1: The influence of the shear rate and temperature on the rheological curves of (a) pure chitosan solution, (b) (90/10), (c) 80/20, (d) 70/30, (e) 60/40, (f) $50 / 50$ and (g) pure agar solutions.

The relationship between shear viscosity (determined at a constant shear rate) and temperature for $\mathrm{CS} / \mathrm{AG}$ blends and the pure components is demonstrated in figure 2 . This graph shows a nearly linear relationship (Table 1) whereby viscosity of the mixture solutions decreases with increasing temperature, i.e., it is a strong function of temperature. It can also be noted that the most effected solution by temperature is the pure agar solution followed by the ratio of $50 / 50$.

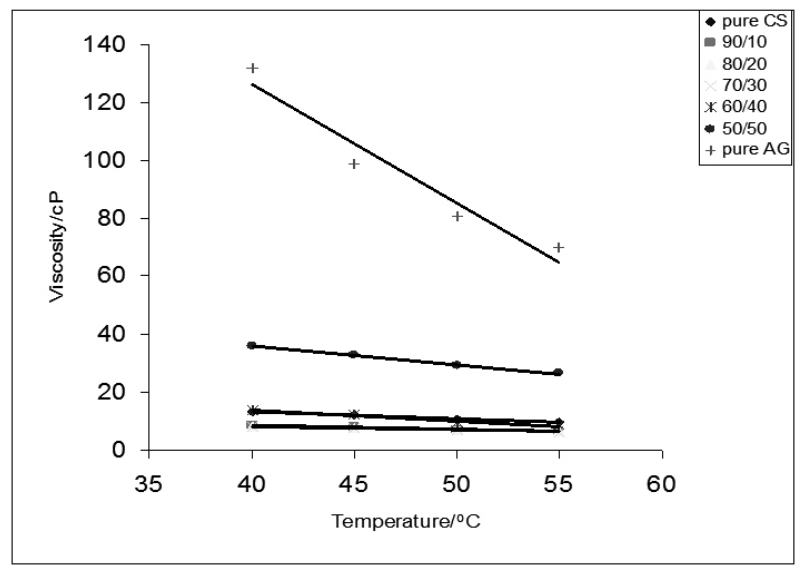

Figure 2: The relationship between the apparent viscosity and the temperature of the blended mixtures at a constant shear rate.

Table 1: Relationship between the $\mathrm{R}^{2}$ and the blend concentration.

\begin{tabular}{|c|c|}
\hline $\mathrm{CS} / \mathrm{AG}$ & $\mathrm{R}^{2}$ \\
\hline $100 / 0$ & 0.9821 \\
\hline $90 / 10$ & 0.9869 \\
\hline $80 / 20$ & 0.9796 \\
\hline $70 / 30$ & 0.9567 \\
\hline $60 / 40$ & 0.9934 \\
\hline $50 / 50$ & 0.9972 \\
\hline $0 / 100$ & 0.9398 \\
\hline
\end{tabular}

The viscosity values obtained at a constant shear rate can be correlated with temperature according to the Arrhenius equation:

$$
\eta=A \cdot e^{-E a / R T}
$$

where $A$ is a constant related to molecular motion, $E_{a}$ is the activation energy for viscous flow at a constant shear rate, $R$ is the gas constant and $T$ is 
the absolute temperature in $\mathrm{K}$. A plot of $\ln$ viscosity as a function of $1 / T$ should produce a straight line and from its slope the Ea can be calculated. Figure 3 presents an Arrhenius plot for various proportions of CS/AG mixture solutions. This graph also shows linear relationships. The values of the apparent activation energy are shown in table 2 .

The value of the activation energy of chitosan is in accordance with the reported values. For example, Wang and Xu (1994) [33] reported that the activation energy varies from $25 \mathrm{~kJ} \mathrm{~mol}^{-1}$ when DD is $91 \%$ to $15 \mathrm{~kJ} \mathrm{~mol}^{-1}$ when $\mathrm{DD}$ is $75 \%$ for a chitosan concentration of $20 \mathrm{~g} \mathrm{~L}^{-1}$ (in $0.2 \mathrm{M} \mathrm{AcOH} / 0.1 \mathrm{M}$ AcONa). Desbrieres (2002) [31] reported values of activation energy at zero shear rate vary from about $15 \mathrm{~kJ} \mathrm{~mol}^{-1}$ to $37 \mathrm{~kJ} \mathrm{~mol}^{-1}$ for a chitosan concentration range between $0 \mathrm{~g} \mathrm{~L}^{-1}$ and $40 \mathrm{~g} \mathrm{~L}^{-1}$ respectively (solvent, $0.3 \mathrm{M} \mathrm{AcOH} / 0.05 \mathrm{M}$ $\mathrm{AcONa})$.

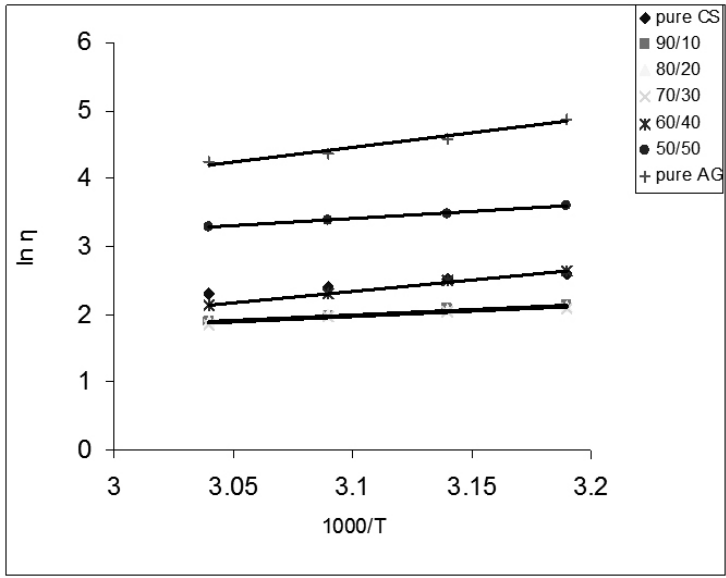

Figure 3: Arrhenius plot of $\ln \eta$ versus $1 / \mathrm{T}$ for the blended solutions.

Table 2: The relationship between the viscous flow activation energy and the blend concentration.

\begin{tabular}{|c|c|c|}
\hline $\mathrm{CS} / \mathrm{AG}$ & $\mathrm{R}^{2}$ & $\begin{array}{l}\text { Viscous flow activation } \\
\text { energy, } \mathrm{E}_{\mathrm{a}}\left(\mathrm{kJ} \mathrm{mol}^{-1}\right)\end{array}$ \\
\hline $100 / 0$ & 0.9795 & 16.79 \\
\hline $90 / 10$ & 0.9877 & 13.30 \\
\hline $80 / 20$ & 0.9675 & 12.30 \\
\hline $70 / 30$ & 0.9477 & 12.97 \\
\hline $60 / 40$ & 0.9959 & 28.27 \\
\hline $50 / 50$ & 0.9996 & 17.29 \\
\hline $0 / 100$ & 0.9758 & 35.41 \\
\hline
\end{tabular}

The effects of shearing and storage time on the apparent viscosity of CS/AG solutions.

Viscosity measurements were performed as a function of shear rate for 15 , $30,45,60$ and 75 seconds at $40^{\circ} \mathrm{C}$ to study the shearing time effect as shown in figure 4 (a-f) (it was difficult to study the effect of shearing time for pure agar due to its random behavior at this temperature). At all shearing times, CS/AG blend solutions exhibit similar behavior and no significant change was observed with exception of the ratio 50/50 wherein increasing in shearing time leaded to decreasing in sharing viscosity and shear stress. In addition, different behaviors were observed for the blend solutions when the period of storage was extended to three weeks at a constant shear rate (Figure 5). Pure chitosan showed gradual increase in viscosity while a drop in viscosity from about $130 \mathrm{cP}$ to $35 \mathrm{cP}$ was recorded within the first week for pure agar, after which it decreased gradually. However, all CS/AG blend solutions recorded a big increase in viscosity within the first and second weeks while a different trend was observed in the third week. The rapid increase in viscosity with time may indicate that some strong interactions have taken place among the chains of the two polymers.

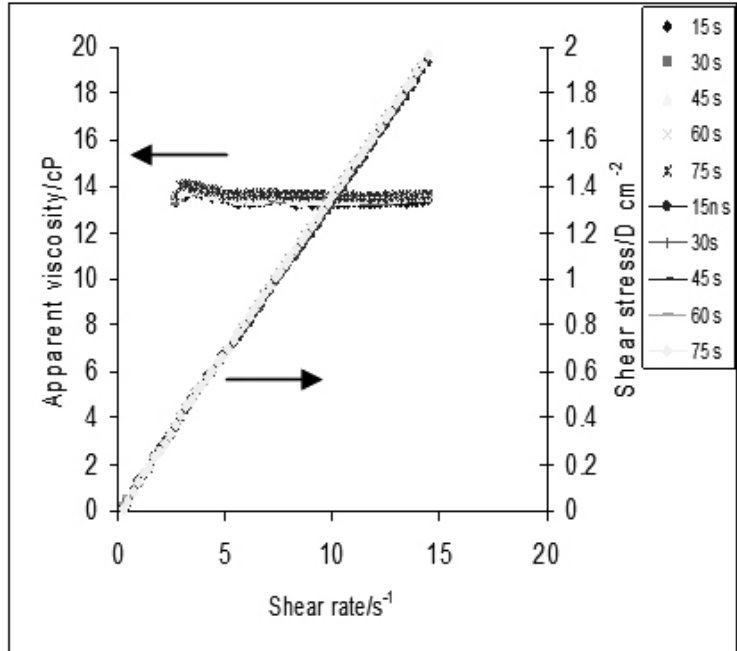

(a)

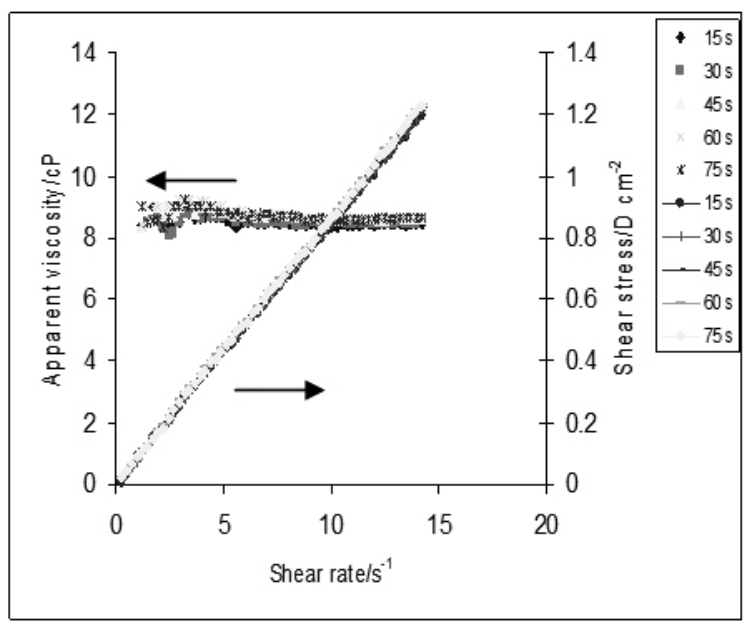

(b)

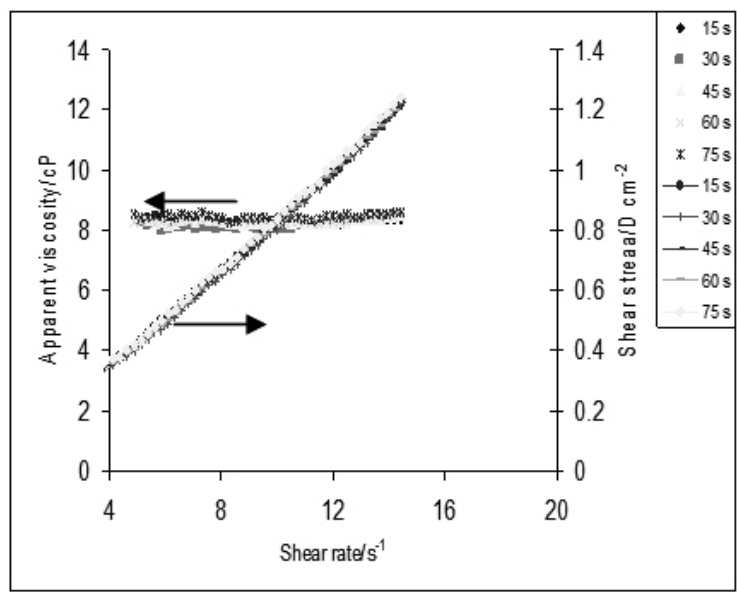

(c) 


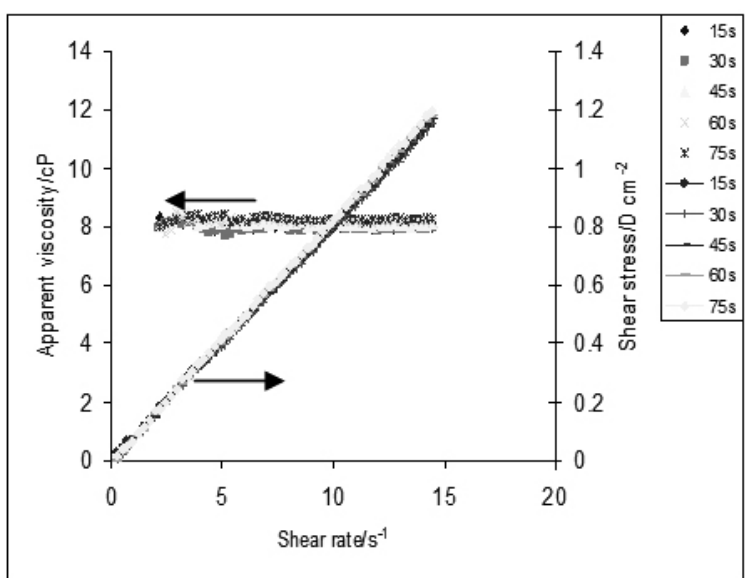

(d)

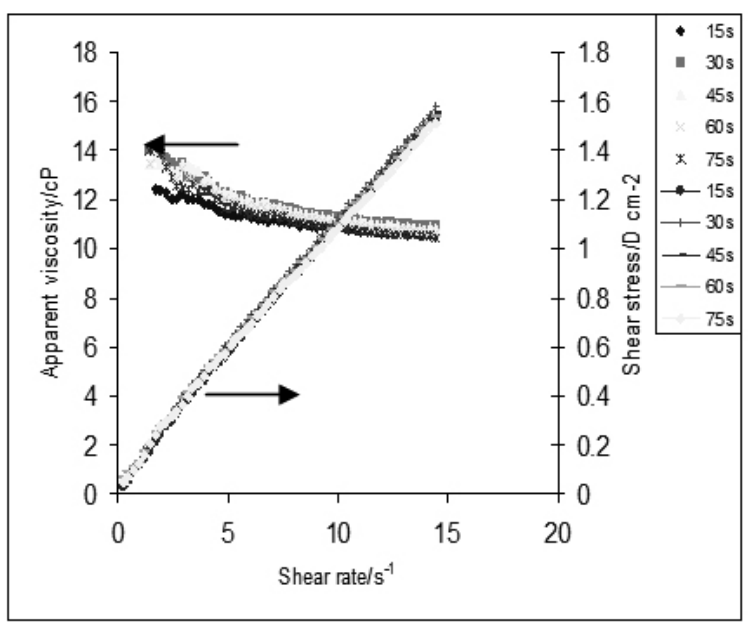

(e)

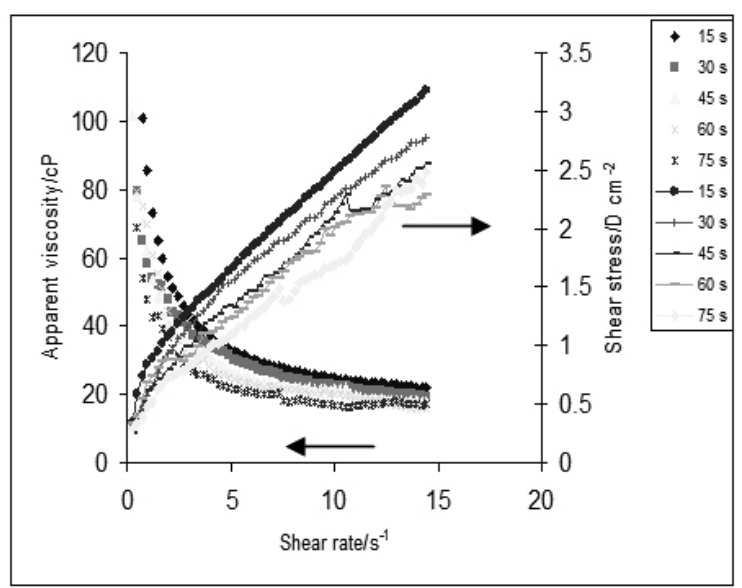

(f)

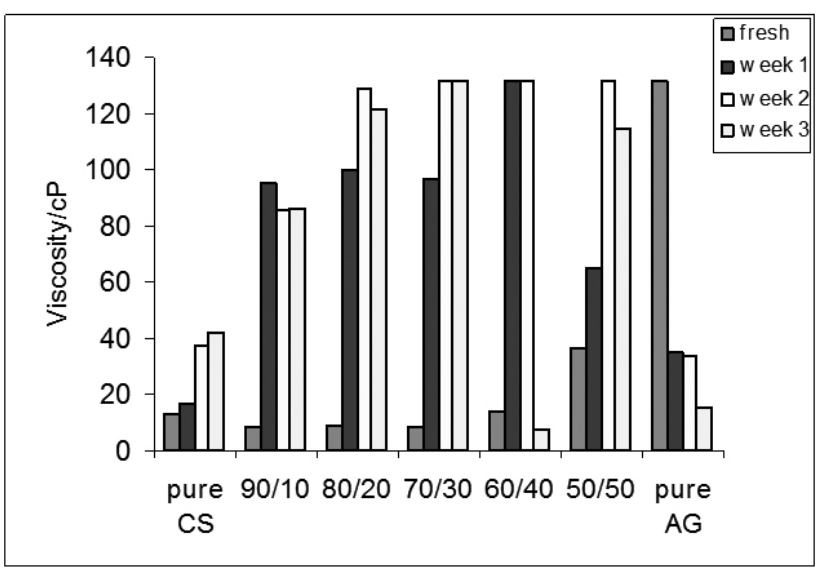

Figure 5: Effect of storage time on the apparent viscosity (determined at a constant shear rate) of CS/AG blend solutions.

\section{FTIR analysis}

The spectra of pure chitosan film and pure agar film are presented in figure 6. The spectrum of pure chitosan film shows a broad band at $3367 \mathrm{~cm}^{-1}$ which is due to the $\mathrm{OH}$ stretching. The band at $1560 \mathrm{~cm}^{-1}$ is assigned for the $\mathrm{NH}$ bending (amide II) $\left(\mathrm{NH}_{2}\right)$ while the small peak at $1647 \mathrm{~cm}^{-1}$ is attributed to the $\mathrm{C}=\mathrm{O}$ stretching (amide I) $\mathrm{O}=\mathrm{C}-\mathrm{NHR}$. The bands at 2927, 2884, 1411, 1321 and $1260 \mathrm{~cm}^{-1}$ are assigned to $\mathrm{CH}_{2}$ bending due to pyranose ring. The band at 1380 $\mathrm{cm}^{-1}$ is due to $\mathrm{CH}_{3}$ wagging. The characteristic features of chitosan spectrum in this study are similar to previous reports [34-36]. FTIR spectrum of agar film shows an absorption band at about $3400 \mathrm{~cm}^{-1}$ which is associated with $\mathrm{O}-\mathrm{H}$ stretching [37] while the peak at $2900 \mathrm{~cm}^{-1}$ is attributed to methoxyl groups [38]. The band at around $1640 \mathrm{~cm}^{-1}$ is due to the stretching of the conjugated peptide bond formed by amine (NH) and acetone (CO) groups [39]. The peak at $1370 \mathrm{~cm}^{-1}$ is assigned to ester sulfate [38] and the bands at 1070 and $930 \mathrm{~cm}^{-1}$ are associated with the 3,6-anhydro-galactose bridges [40].

The FTIR spectra of chitosan and agar blend films containing various agar proportions are also shown in figure 6. A summary of characteristic bands of chitosan and agar blend films is presented in Table 3. As can be seen, the increase in the agar content in the blend films caused a decrease in the intensity of the band arising from the NH bending (amide II) at $1560 \mathrm{~cm}^{-1}$ of chitosan. This was coupled with a similar decrease in the absorbance band at $1411 \mathrm{~cm}^{-1}$ and an increase of band absorbance at $1380 \mathrm{~cm}^{-1}$. Furthermore, the spectra of blend films show the disappearance of the intensive band at $1033 \mathrm{~cm}^{-1}$ that was obviously observed in the pure chitosan film and chitosan/agar blend containing agar content of $10 \%$. This is due to the fact that when two or more polymers are mixed, changes in characteristic peaks occur as a reflection of the physical and chemical interactions $[41,42]$. These observations indicate the existence of good miscibility between chitosan and agar that is most likely caused by the formation of intermolecular hydrogen bonds between the amino and hydroxyl groups in chitosan and the hydroxyl groups in agar.

Figure 4: The influence of the shear rate and shearing time on the rheological curves of (a) pure chitosan solution, (b) $(90 / 10)$, (c) 80/20, (d) $70 / 30$, (e) $60 / 40$ and (f) $50 / 50$ at $40^{\circ} \mathrm{C}$. 


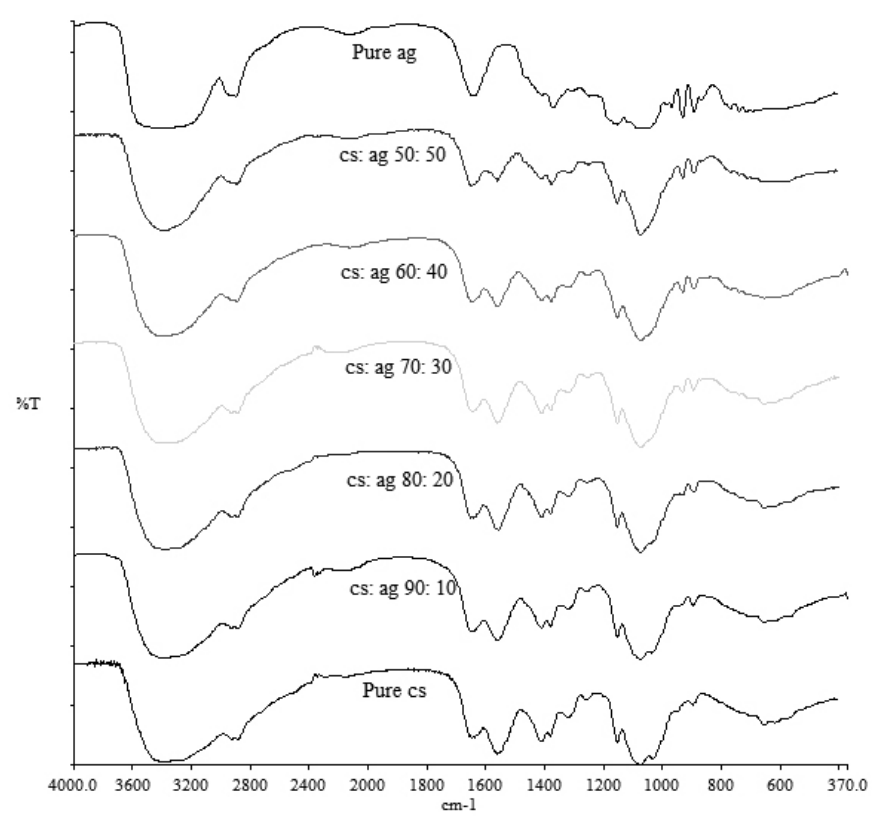

Figure 6: Typical FTIR spectra of chitosan/agar blend films having various proportions.

Table 3: FTIR characteristic bands of chitosan/agar blend films.

\begin{tabular}{|c|c|c|c|c|c|c|}
\hline $\begin{array}{c}\text { Chitosan/ } \\
\text { agar } \\
(\%)\end{array}$ & $\mathrm{OH}$ & $\begin{array}{c}\mathrm{C}=\mathrm{O} \\
(\text { amide I })\end{array}$ & $\begin{array}{c}\mathrm{NH} \\
(\mathrm{amide} \\
\mathrm{II})\end{array}$ & $\begin{array}{c}\mathrm{CH} \\
(\mathrm{amide} \\
\mathrm{II})\end{array}$ & $\mathrm{C}-\mathrm{C}$ & $\mathrm{C}-\mathrm{O}$ \\
\hline $100 / 0$ & 3368 & 1648 & 1561 & 1411 & 1380 & 1033 \\
\hline $90 / 10$ & 3368 & 1647 & 1559 & 1412 & 1379 & 1035 \\
\hline $80 / 20$ & 3371 & 1651 & 1558 & 1411 & 1379 & - \\
\hline $70 / 30$ & 3368 & 1646 & 1559 & 1411 & 1379 & - \\
\hline $60 / 40$ & 3371 & 1647 & 1560 & 1412 & 1378 & - \\
\hline $50 / 50$ & 3379 & 1647 & 1559 & 1417 & 1376 & - \\
\hline $0 / 100$ & 3400 & 1643 & - & 1409 & 1373 & - \\
\hline
\end{tabular}

\section{Thermal properties}

Figure 7 shows the DSC first run curves of pure chitosan film, pure agar film and their blended films. After drying, all samples were kept in a desiccator before analysis. All compositions exhibited a broad endothermic peak at a different position ranging from about $75^{\circ} \mathrm{C}$ to $84^{\circ} \mathrm{C}$ (Table 4). Similar endothermic peaks have been reported in the literature for chitosan film. For example, Lima et al [43] and Wang et al [44] reported an endothermic peak of chitosan film at $60.75^{\circ} \mathrm{C}$ and $83^{\circ} \mathrm{C}$ for fully deacetylated chitosan and $85 \%$ DD respectively. As for pure agar, Eldridge and Ferry [45] demonstrated that agar film exhibits an endothermic peak at around $90^{\circ} \mathrm{C}$ while Lyons et al [46] found that the agar film shows an endothermic peak at $110^{\circ} \mathrm{C}$ which is higher than the usual reported value. Also, Suzuki et al [47] reported endothermic peaks of three kinds of agar gel at different positions ranging from $75^{\circ} \mathrm{C}$ to $90^{\circ} \mathrm{C}$. According to some authors, this endothermic peak is related to the melting temperature [48]. However, it is often termed as dehydration temperature $\left(T_{\mathrm{D}}\right)$, attributed to the evaporation of water associated with the hydrophilic groups of the polymers $[49,50]$ and reflects the strength of water-polymer interaction $[51,52]$. This suggests that some bound water was still not removed from the samples when dried in the desiccator. These endothermic peaks were absent in the second run curve (not shown here) which confirmed that this peak is attributed to the water content in the sample. A closer examination of Figure 7 reveals that there is a difference in the endothermic peak area for the membranes, i.e., they vary in their water-holding capacity, showing that the blended films have higher water content in general than the pure components. This could be due to the formation of new hydrophilic centers [53]. Another point to be noted is that all ratios have close values of $T_{\mathrm{D}}$ to the values of the pure polymers except for the ratio $60 / 40$ which shows a higher value. The shift of the peak position to a higher temperature indicates a stronger interaction with water. It is believed that this variation on the position and peak area is due to the physical and molecular changes caused by blending. These results suggest that the interaction between chitosan and agar may occur to form films with more stability.

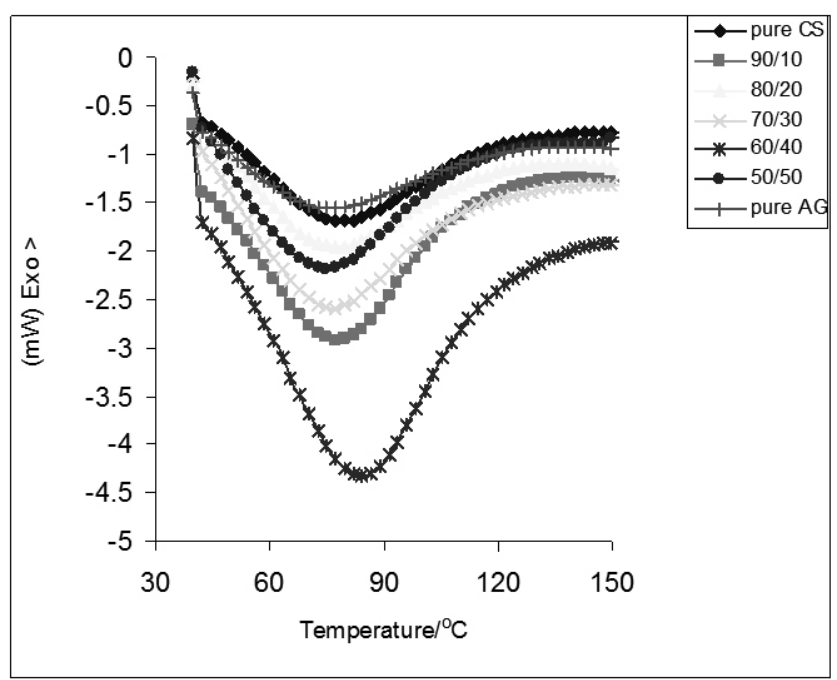

Figure 7: The DSC first run curves of pure chitosan, pure agar and their blended films.

Table 4: The thermal properties of chitosan/agar blends with different agar content.

\begin{tabular}{|c|c|c|c|c|c|c|c|}
\hline $\begin{array}{c}\text { Chitosan } \\
\text { content }(\%)\end{array}$ & 100 & 90 & 80 & 70 & 60 & 50 & 0 \\
\hline $\begin{array}{c}\mathrm{T}_{\mathrm{D}}\left({ }^{\circ} \mathrm{C}\right) \\
\text { (dehydration } \\
\text { temperature) }\end{array}$ & 78.8 & 78.4 & 77.4 & 75.7 & 83.8 & 74.8 & 75.3 \\
\hline $\begin{array}{c}\Delta \mathrm{H}(\mathrm{J} / \mathrm{g}) \\
\text { dehydration } \\
\text { energy) }\end{array}$ & 227.6 & 235.9 & 260.6 & 336.6 & 362.5 & 325.3 & 240.5 \\
\hline
\end{tabular}

With respect to the glass transition temperature $\left(\mathrm{T}_{\mathrm{g}}\right)$ of chitosan, various values have been reported in the literature ranging from $-23^{\circ} \mathrm{C}$ to about $220^{\circ} \mathrm{C}$ [48,52,54-57] (Table 5). The variations on the values of the $\mathrm{Tg}$ of chitosan is probably due to the difficulty in identifying it since chitosan is semicrystalline [58] as well as due to the large amount of intra-and intermolecular hydrogen bonds in its chain [59]. In addition, being a natural polysaccharide, the source and the method of preparation of chitosan can influence its $\mathrm{T}_{\mathrm{g}}$ [53]. In this work, the $\mathrm{T}_{\mathrm{g}}$ of chitosan could not be detected.

Table 5: The values of $\mathrm{Tg}$ reported in the literature.

\begin{tabular}{|c|c|c|c|c|c|c|}
\hline $\mathrm{T}_{\mathrm{g}}\left({ }^{\circ} \mathrm{C}\right)$ & 194 & 150 & $\sim 220$ & 30 & $\begin{array}{c}\text { from }-23 \\
\text { to } 67\end{array}$ & 203 \\
\hline Ref & 49 & 50 & 51 & 52 & 53 & 47 \\
\hline
\end{tabular}

\section{CONCLUSION}

This study has shown that the pseudoplastic non-Newtonian behavior was observed only for the ratios $60 / 40$ and 50/50 of chitosan/agar blends at the range of temperature studied. In addition, the relationship between the shearing viscosity and the temperature could be described with the Arrhenius equation. This study has also shown that curves of the apparent viscosity of pure chitosan, pure agar and their blended solutions exhibited similar behavior at all shearing times of 15-75 s. However, the ratio 50/50 exhibited a decrease in viscosity and shear stress with increasing shear rate. Furthermore, different 
behaviors were observed for the blend solutions when the period of storage was extended to three weeks, but an increase in viscosity for all blends within the first and second weeks was observed. The rapid increase in viscosity with time may indicate that some strong interactions have taken place among the chains of the two polymers. The interaction between chitosan and agar was confirmed by FTIR and DSC.

\section{References}

[1] M. Ratajska, S. Boryniec, React. Funct. Polym. 38, 35, (1998).

[2] Y. H. Bae, S. W. Kim, Adv. Drug. Delivery. Rev. 11, 109, (1993).

[3] J. Hosokawa, M. Nishiyama, K. Yoshihara, T. Kubo, Ind. Eng. Chem. Res. 29, 800, (1990)

[4] M. Hasegawa, A. Isogai, F. Onabe, M. Usuda, R. H. Atalla, J. Appl. Polym. Sci. 45. 1873, (1992).

[5] Y. X. Xu, K. M. Kim, M. A. Hanna, D. Nag, Ind. Crop Prod. 21. 185, (2005).

[6] M. Cheng, J. Deng, F. Yang, Y. Gong, N. Zhao, X. Zhang, Biomaterials. 24. 2871, (2003).

[7] Y. Ye, W. Dan, R. Zeng, H. Lin, N. Dan, L. Guan, Z. Mi, Eur. Polym. J. 43. 2066, (2007).

[8] C. Sandoval, C. Castro, L. Gargallo, D. Radic, J. Freire, Polymer. 46, 10437, (2005).

[9] R. A. A. Muzzarelli, Natural Chelating Polymers, Pergamon Press Ltd, London, (1973).

[10] Y. W. Cho, Y. N. Cho, S. H. Chung, W, Ko, Biomaterials. 20, 2139 , (1999).

[11] O. Pillai, R. Panchagnula, Curr. Opin. Chem. Biol. 5, 447, (2001).

[12] E. Khor, L. Y. Lim, Biomater. 24, 2339, (2003).

[13] S. Yuan, T, Wei, J. Bioact. Compat. Polym. 19, 467, (2004).

[14] G. Crini, Bioresour. Technol. 97, 1061, (2006).

[15] H. Moritaka, M. Takahashi, K. Kuboa, Food Sci. Technol. Res. 13, 345, (2007).

[16] A. M. Stephen, G. O. Phillips, P.A. Williams, Food Polysaccharides and Their Applications, Marcel Dekker Inc, New York, Basel, 1995.

[17] G. J. Lyons, L. M. Geever, M. J. D. Nugent, J. E. Kennedy, C. L. Higginbotha, J. Mech. Behav. Biomed. Mat. 2, 485, (2009).

[18] R. Armisen, F. Galatas, Agar in G. O. Philips and P. A.Williams eds, Handbook of hydrocolloids New York, CRC Press, 2000; pp. 21-40.

[19] J. Rosiak, P. Ulanski, A. Rzeznicki, Nucl. Instrum. Methods Phys. Res., Sect. B. 105, 335, (1995).

[20] R. Armisen, J. Appl. Phycol. 7. 231, (1995).

[21] Y. Freile-Pelegrín, T, Madera-Santana, D. Robledo, L. Veleva, P. Quintana, J. A. Azamar.. Polym. Degrad. Stab. 1-9, (2006).

[22] M. Cheng, J. Deng, F. Yang, Y. Gong, N, Zhao, X, Zhang, Biomaterials. 24, 2871, (2003).

[23] Y. Ye, W. Dan, R, Zeng, H. Lin, N. Dan, L. Guan, Z. Mi, Eur. Polym. J. 43. 2066, (2007).

[24] Y. W. Cho, Y. N. Cho, S. H. Chung, W. Ko, Biomaterials. 20, 2139, (1999).

[25] O. Pillai, R. Panchagnula, Curr. Opin. Chem. Biol. 5, 447, (2001).

[26] A. Sionkowska, M. Wisniewski, J. Skopinska, G. F. Poggi, E. Marsano, C. A. Maxwell, T. J. Wess, Polym. Degrad. Stab. 91, 3026, (2006).
[27] L. Balau, G. Lisa, M. I. Popa, V. Tura, V. Melnig, CEJC. 2, 638, (2004).

[28] J. Estrela dos Santos, E. R. Dockal, E. T. G. Cavalheiro, J. Therm. Anal. Calorim. 79, 243, (2005).

[29] C. G. T. Neto, J. A. Giacometti, A. E. Job, F. C. Ferreira, J. L. C. Fonseca, M. R. Pereira, Carbohydr. Polym. 62. 97, (2005).

[30] R. A. A. Muzzarelli, R. Rochetti, Carbohydr. Polym. 5, 461, (1985).

[31] J. Desbrie'res, Biomacromol. 3. 342, (2002).

[32] F. Delben, R. Lapasin, S. Pricl. Int. J. Biol. Macromol. 12, 9, (1990).

[33] W. Wang, D. Xu, Int. J. Biol. Macromol. 16, 149, (1994).

[34] J. Nunthanid, S. Puttipipatkhachorn, K. Yamamoto, G. E. Peck, Drug. Dev. Ind. Pharm. 27, 143, (2001).

[35] G. C. Ritthidej, T. Phaechamud, T. Koizumi, Int. J. Pharm. 232, 11, (2002).

[36] Y. X. Xu, K. M. Kim, M. A. Hanna, D. Nag, Ind. Crops Prod. 21, 185, (2005)

[37] M. Tako, M. Higa, K. Medoruma, Y. Nakasone, Bot. Mar. 42, 513, (1999).

[38] R. Armise'n, F. Galatas, FAO Fish. Tech. Papers. 288, 1, (1987).

[39] D. Cristiaen, M. Bodard, Bot. Mar. 26, 425, (1983).

[40] A. Chirapart, M. Ohno, H. Ukeda, M. Sawamura, H. Kusunose, Appl. Phycol. 7, 359, (1995).

[41] Y. L. Guan, X. F. Liu, Y. P. Zhang, K. D. Yao, J. Appl. Polym. Sci. 67, 1965, (1998)

[42] Y. J. Yin, K. D. Yao, G. X. Cheng, J. B. Ma, Polym. Int. 48, 429, (1999).

[43] C. G. A. Lima, R. S. De Oliveira, S. D. Figueiro, C. F. Wehmann, J. C. Goes Sombra, A. S. B. Ombra, Mater. chem. phys. 99. 284, (2006).

[44] Y. C. Wang, M. C. Lin, D. M. Wang, H. J. Hsieh, Biomaterials. 24, 1047, (2003).

[45] J. Eldridge, J. Ferry. J. Phys. Chem. 58, 992, (1954).

[46] G. L. John, M. G. Luke, J. D. N. Michael, E. K. James, L. H. Clement. Journal of the Mechanical Behavior of Biomedical Materials. 2, 485, (2009).

[47] H. Suzuki, Y. Sawai, M. Takada, Food Sci. Technol. Res. 7, 280, (2001).

[48] N. E. Suyatma, A. Copinet, L. Tighzert and V. Coma, J. Polym. Environ. $12,1,(2004)$

[49] M. K. Cheung, K. P. Y. Wan, P. H. Yu, J. Appl. Polym. Sci. 86, 1253, (2002).

[50] V. Gonzalez, C. Guerrero, U. Ortiz. J. Appl. Polym. Sci. 78, 850, (2000).

[51] F. S. Kittur, K. V. H. Prashanth, K.U. Sankar, R. N. Tharanathan, Carbohydr. Polym. 49, 185, (2002).

[52] K. Sakurai, T. Maegawa, T. Takahashi, Polymer. 41, 7051, (2000).

[53] C. G.T. Neto, J. A. Giacometti, A. E. Job, F. C. Ferreira, J. L.C. Fonseca, M. R. Pereira. Carbohydr. Polym. 62, 97, (2005).

[54] K. Ogura, T. Kanamoto, M. Itoh, H. Miyashiro, K. Tanaka. Polym Bull. 2, 301, (1980).

[55] M. Pizzoli, G. Ceccorulli, M. Scandola, Carbohydr. Res. 222, 205, (1991).

[56] J. Ratto, T. Hatakeyama, R. B. Blumstein, Polymer, 36, 2915, (1995)

[57] A. Lazaridou, C. G. Biliaderis, Carbohydr. Polym. 48, 179, (2005).

[58] C. Chen, F. Wang, C. Mao, W. Liao, C. Hsieh. Int. J. Biol. Macromol. 43, 37, (2008).

[59] Z. Cai and J. Kim, Smart Mater. Struct. 17, 035028, (2008). 